\title{
GELANGGANG DIA.LO.GUE, DI KELURAHAN MERUYA UTARA
}

\author{
Kevin Hartanto ${ }^{1)}$, Tatang Hendra Pangestu ${ }^{2)}$ \\ 1)Program Studi S1 Arsitektur, Fakultas Teknik, Universitas Tarumanagara, kevinhartanto18@gmail.com \\ ${ }^{2)}$ Program Studi 11 Arsitektur, Fakultas Teknik, Universitas Tarumanagara, \\ tatang_pangestu@hotmail.com
}

Masuk: 14-07-2020, revisi: 31-07-2020, diterima untuk diterbitkan: 24-09-2020

\begin{abstract}
Abstrak
Pada kelurahan meruya ada sebuah masalah yakni perpecahan antara warga Taman Aries dan Taman Meruya yang susah diselsaikan karena kurangnya kesadaran akan warga masyarakat sehingga kejadian konflik yang di teruskan dan di sebarluaskan hanya kebencian, kurangnya interaksi sosial secara fisik dan lainya, saya bermimpi dan memiliki sebuah kerinduan untuk merangkul dan membantu mempersatukan kembali kedua belah pihak warga. Mengambil konsep dari Forum Romawi dan Yunani, pada jamannya kerajaan Romawi dan Yunani memiliki sebuah area terbuka dan diapit beberapa bangunan, yang di gunakan untuk rapat antar kepala keluarga, rapat antar kepala desa, bahkan rapat untuk perang. Tetapi saat tidak digunakan untuk perang tempat itu merupakan tempat berkumpul para warga untuk berinteraksi sosial, bertukar pikiran, menampilkan karya seni, hingga menyediakan beragam makanan. Yang akan menjadi tujuan utama dari proyek ini adalah untuk menciptakan "forum" untuk warga agar dapat menyuarakan pendapat, bermusyawarah bertukar pikiran dan pendapat. Tujuan lainnya adalah untuk menampung kegiatan warga yang sekarang tidak pada tempatnya. Menyediakan tempat bekerja untuk mayoritas penduduk untuk mengerjakan tugas (40\% siswa dan mahasiswa, dan terus bertambah tiap tahunnya). Dan dibuatkan third place yang nyaman bagi warga masyarakat Meruya Utara.
\end{abstract}

Kata kunci: forum; komunikasi; mempersatukan; perpecahan

\begin{abstract}
The issue on the North Meruya Urban Area is the visible splitting of 2 urban housing areas of Taman Aries and Taman Meruya. The visible splitting was due to an old problem that has changed the perception of both people living in those areas. Because it is an old problem that most people had forgotten, the resentment still follows on to the next generation, creating a never ending splitting issue due to hate. I have a dream that one day, this project maybe able to help reunite those two urban housing areas and live together as a big North Meruya Family. Taking concept from Roman and Greek Forums, a Forum is a Large open area surronded by a couple of buildings, and could be use as an area for small to big meetings, open theaters, music performance, generally a place where people can gather and interact socially, and exchange thoughts. The main focus of this project is to make a "Forum" for the people of North Meruya to voice their opinion, communicate, and solve problems together instead of saving resentment, a place where the people of North Meruya can showcase art, a place for a majority of North Meruya people (consisting of $40 \%$ students and increasing) to work together. And become a comfortable thirdplace for the people of North Meruya.
\end{abstract}

Keywords: communication, forum, reunite, splitting 


\section{PENDAHULUAN}

\section{Latar Belakang}

Arsitektur berkembang bedasarkan masyarakatnya, selalu direncanakan dan dirancang, bukan terbentuk sendirinya. Arsitektur berkembang dengan tujuan. Arsitektur bukanlah benda "Mati" yang sifatnya tetap melainkan terus berkembang seiring dengan perubahan masyarakat dan budayanya. Dalam ranah social behaviour, the third place merupakan tempat penting yang merupakan kebutuhan masyarakat, selain dari rumah (1st place) maupun tempat kerjanya (2nd place). Third place adalah tempat public yang netral, sebagai tempat alternative, siapapun dapat kesana, dapat digunakan untuk berbagai aktivitas, dapat di gunakan siapa saja. Third place ada dimana-mana dan memiliki bentuk yang beragam sesuai dengan kehidupan dan budaya masyarakat setempat.

Pada site yang dipilih, telah lama bermunculan masalah perpecahan antar warga. Meruya merupakan sebuah kelurahan besar yang awalnya bermula dari warga Betawi yang bercocok tanam, padi, sayur dan buah buah seperti belimbing dan manga, tidak seperti kelurahan Kembangan yang banyak menanam bunga. Lalu suatu hari datang sebuah perusahaan besar yang membuat perumahan elite, telah membebaskan lahan para warga meruya untuk dijadikan rumah rumah mewah besar dan luas sehingga membuat warga Betawi meruya marah. kemudian dating pula beberapa perusahaan membangun sebuah komplek perumahan menengah keatas dan bangunan-bangunan rumah berlantai rendah diatas sisa lahan yang ada. Kedua perumahan seakan-akan merebutapa yang harusnya di miliki oleh warga Betawi asli Meruya dan oleh sebab itu mulailah terjadi gesekan antar warga Betawi dengan warga ras lainya.

Menurut hasil wawancara dengan narasumber, Bpk. Haji Juhri, seorang petinggi komunitas Betawi di Meruya, beliau mengatakan memang betul ada gesekan antar beberapa ras dengan warga Betawi, sudah beberapa kali ber konfrontasi dan berantem juga. Pak Haji melanjutkan dengan mengatakan warganya merasa terbagi 3 wilayah yang sama sekali tidak terkoneksi, wilayah Aries (Chinese, Jawa), Intercon (Chinese), Dan Taman Meruya (Betawi), sedang warga ras lain malas bermain ke taman Meruya, begitu pula sebaliknya warga Betawi malas bermain ke wilayah Aries. Menurutnya, gaya hidup ini tidak sehat dan suatu saat akan menimbulkan perpecahan (Juhri, 2020). Selain wawancara, survey berformulir di berikan pada 100 warga Aries dan hasilnya $80 \%$ tidak mengetahui adanya warga Betawi yang tinggal pada taman meruya, bahkan $82 \%$ warga mengetahui siapa yang tinggal di rumah sampingnya, namun hanya $18 \%$ warga yang saling kenal dengan tetangganya.

Meruya Utara memiliki 50 sekolah, dan wilayah dengan sekolah sebanyak ini, ternyata tidak memiliki fasilitas dimana para pelajar dapat berkumpul dan mengerjakan tugas Bersama, tidak ada fasilitas seperti ruang membaca dengan koleksi buku yang lengkap, tidak ada tempat kerja kelompok yang formal, sehingga kerja kolompok terbatasi sampai sekolah tutup atau hanya terbatasi oleh rumah masing masing. Munculnya third place dapat membantu menyelsaikan masalah ini, dengan membangun common ground dimana warga dapat menjadi neutral, level, dan playful. Tempat ini juga dapat mendorong agar para warga manapun datang dan berinteraksi, berkomunikasi, bertukar pengetahuan dan diharapkan dapat memulihkan luka lama yang telah mendalam

\section{Rumusan Permasalahan}

Masalah yang ingin di selesaikan antara lain:

a. Ruang seperti apa yang dapat membantu mempersatukan warga?

b. Bagaimana cara agar berkomunikasi dapat di kolaborasikan di tempat ini?

c. Bagaimana cara menanamkan aspek "Level" atau kesetaraan di dalam tempat ini? 
d. Bagaimana cara membuat ruang yang dapat membuat kedua belah pihak warga untuk saling berinteraksi (sosial maupun kegiatan)?

e. Bagaimana cara untuk mengkolaborasikan antara bangunan third place dengan open architecture?

\section{Tujuan}

Merangkul dan membantu mempersatukan kembali kedua belah pihak warga yang telah rusak karena waktu. Menggunakan konsep forum romawi dan Yunani untuk menciptakan tempat yang tidak memandang bulu kalangan apapun di kelurahan meruya utara, untuk menciptakan tempat dimana warga dapaet menyuarakan pendapat, saling bertukar pikiran dan saling menerima, sebuah tempat dimana warga dapat tempat kedua yang dapat dibilang rumah kedua, untuk menciptakan warga dapat relaksasi dan mengekspresikan diri dengan seni dari bermusik, menari, puisi, dst, untuk menampung kegiatan warga yang sekarang tidak pada tempatnya. Menyediakan tempat bekerja untuk mayoritas penduduk untuk mengerjakan tugas (40\% siswa dan mahasiswa, dan terus bertambah tiap tahunya). Dan menjadi third place yang nyaman bagi warga Meruya Utara.

\section{KAJIAN LITERATUR}

\section{Third Place}

Mendesain third place, mulai dari first place yang sering diartikan dengan rumah, atau tempat dimana kita memulai aktifitas awal kita, lalu second place yang sering diartikan dengan tempat kerja, atau tempat dimana kita melaksanakan kewajiban kita, baik itu tempat kerja atau tempat belajar. Lalu ada third place yang sering diartikan dengan tempat perantara, dimana kita datang untuk memenuhi kebutuhan sosialisasi dan bertukar pikiran (Oldenberg, 2002). Menurut Oldenburg (2002), third place ini memiliki 8 karakteristik yaitu:

\section{a. Neutral Ground}

Sebuah tempat dimana para pengunjung tidak terikat dan terbebani oleh kasta finansial, politik, agama, dll. Dan merukapan sebuah tempat yang dapat membahas hal hal yang lebih bersifat umum

b. Level

Status sosial, ekonomi, jabatan, dll, tidak dipentingkan dalam third place sehingga membuat semua orang menjadi 1 kasta dan menghindari penolakan individual dalam komunitas.

c. Conversation is the Main Activity

Focus utama third place adalah meningkatkan komunikasi antar pengguna third place dan menjadikan third place menjadi pusat interaksi antar pengguna dalam cakupan kelurahan.

d. Accessibility and Accommodation

Sebuah third place harus siap secara aksesibilitas terhadap penggunanya dan dapat membuat penggunanya merasa kebutuhanya terpenuhi. Seperti akses ke halte atau stasiun.

e. Regulars

Memiliki pengguna yang sering datang dan membentuk karakter dari tempaat tersebut serta dapan memancing datangnya pengguna baru.

f. Low Profile

Tidak membesar besarkan atau membuah tempatnya megah, tempat yang sederhada yang dapat membuat para penggunanya merasakan nyaman seperti di rumah.

g. Playful

Tempat memiliki kesan ceria, mengundang dan senang, sehingga tidak ada kesan tekanan atau stress, karena pada dasarnya tempat ini di rancang untuk membawa dan membaur para warga dengan netral dan leveling.

h. A Home away from Home

Menjadi rumah kedua bagi pengguna third place, dengan menciptakan kehanganan dan membangkit sense of belonging warga. (Oldenberg, 2002) 


\section{Interaksi Sosial}

Manusia adalah makhluk sosial, manusia tidak akan dapat hidup sebagai manusia apabila tidak hidup diantara manusia lainnya. Dengan adanya bantuan dari manusia atau individu lain maka seorang manusia akan dapat berdiri tegak. Interaksi sosial merupakan hubungan timbal balik yang terjadi antara individu dengan individu, individu dengan kelompok, maupun kelompok dengan kelompok. Ketika antar individu maupun kelompok manusia saling berhubungan maka saat itu sedang terjadi aktivitas dari interaksi sosial. Interaksi sosial dapat berupa interaksi langsung dan tidak langsung. Interaksi sangat berguna sekali dalam kepentingan kehidupan sehari-hari manusia. Untuk memenuhi kebutuhannya manusia harus melakukan proses interaksi sosial. Adapun syarat-syarat terjadinya interaksi sosial salah satunya adalah kontak sosial, yaitu suatu kegiatan individu atau kelompok dengan bentuk isyarat yang mempunyai makna untuk pelaku dan penerima. Jenis kontak sosial:

a. Terjadi antarindividu, antar kelompok, dan antara individu dengan kelompok.

b. Kontak sosial dapat terjadi secara langsung dan tidak langsung.

c. Kontak sosial bersifat positif atau negatif. Kontak sosial positif dapat menimbulkan suatu kerjasama, sedangkan kontak sosial negatif dapat menimbulkan konflik atau pertentangan.

d. Kontak sosial primer dan sekunder. Kontak sosial primer terjadi ketika individu yang berinteraksi bertemu secara langsung dan bertatap muka. Sedangkan kontak sosial sekunder terjadi ketika interaksi dilakukan melalui perantara, seperti telpon, mengirim surat, dan lainnya sebagainya (King, 2008).

\section{Forum}

Forum pada jaman Romawi merupakan salah satu area pada kota dimana menjadi pusat interaksi sosial warga Romawi. Forum tersebut merupakan tempat yang terbuka di antara bangunan bangunan yang fungsinya terdukung oleh forum ini. Selain menjadi pust interaksi sosial antar warga, forum Romawi kerap digunakan untuk berdiskusi permasalahan kota, penyuaraan pendapat jika ada keputusan pemerintah yang tidak di setujui, permainan alat musik dan street performance, penjualan makanan dan minuman, dan rapat rapat lainya (History.com, 2018)

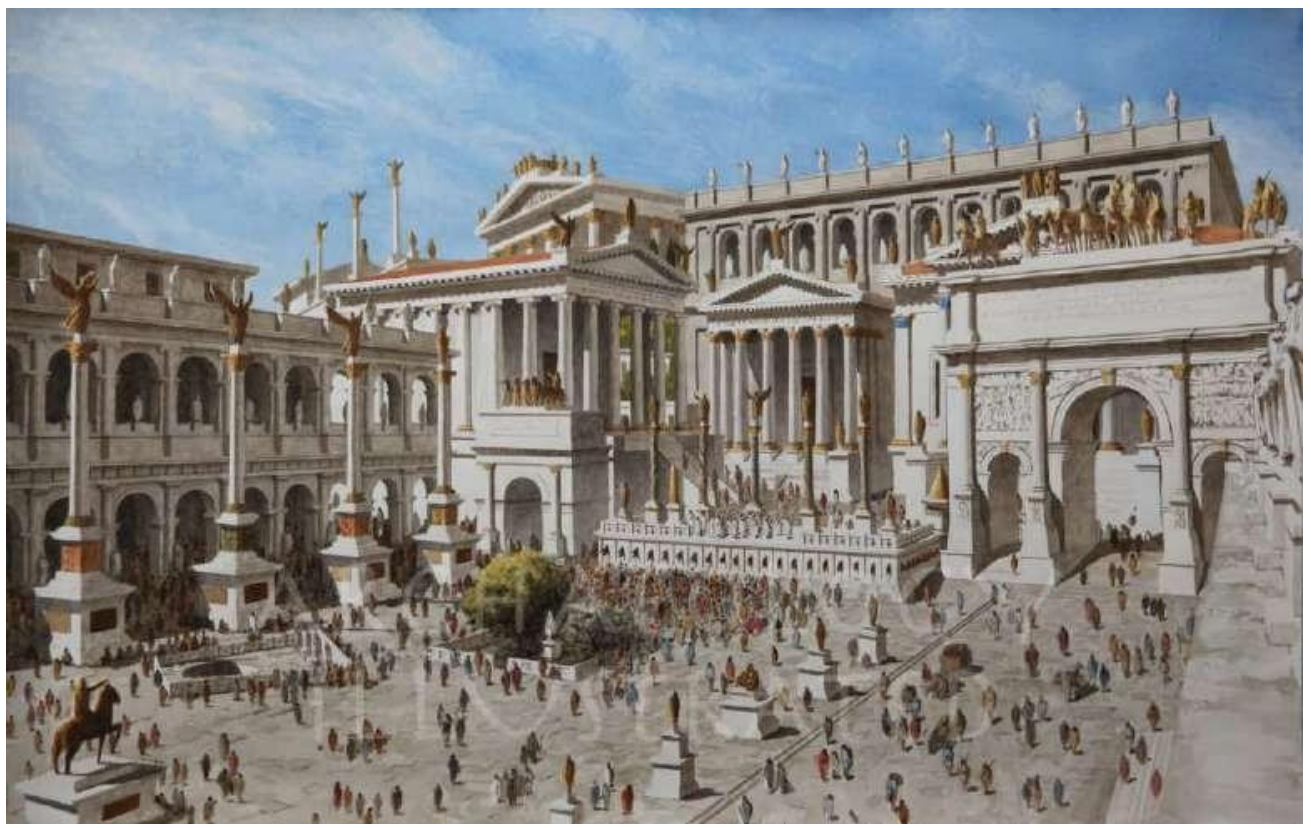

Gambar 1. Forum Romawi

Sumber: https://archaeologyillustrated.com/collections/rome-the-roman-forum-3rd-century-ad/ 
Pada forum Yunani, ada sebuah perbedaan dalam forum, dan kegiatan forum lebih di privatekan untuk rapat antar kepala keluarga atau antara kepala desa dan membahas hal yang bersifat politik. Tetapi saat sedang tidak di gunakan, forum ini dapat di gunakan sebagai tempat berkumpul dan berinteraksi sosial, serta menjadi sebuah teater (History.com, 2018).

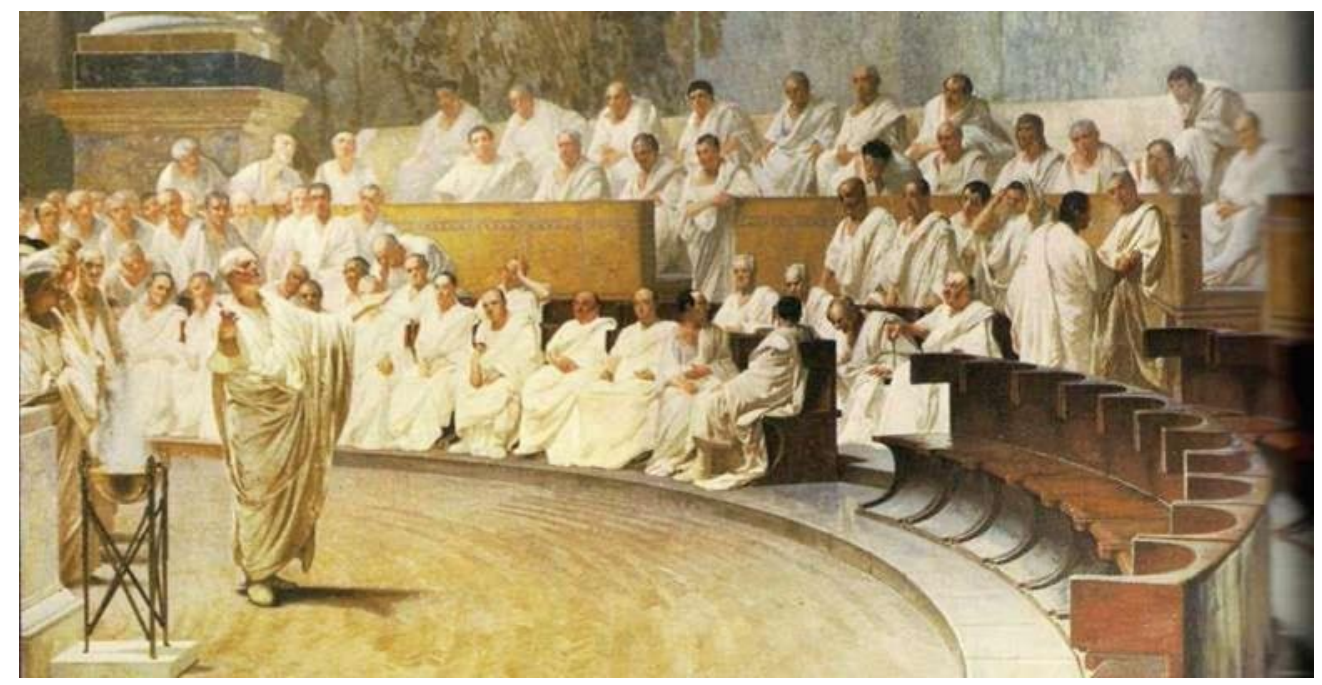

Gambar 2. Forum Yunani (para kepala desa sedang berkumpul membahas peraturan negara/politik)

Sumber: https://ethology.eu/forums/greek-forum/

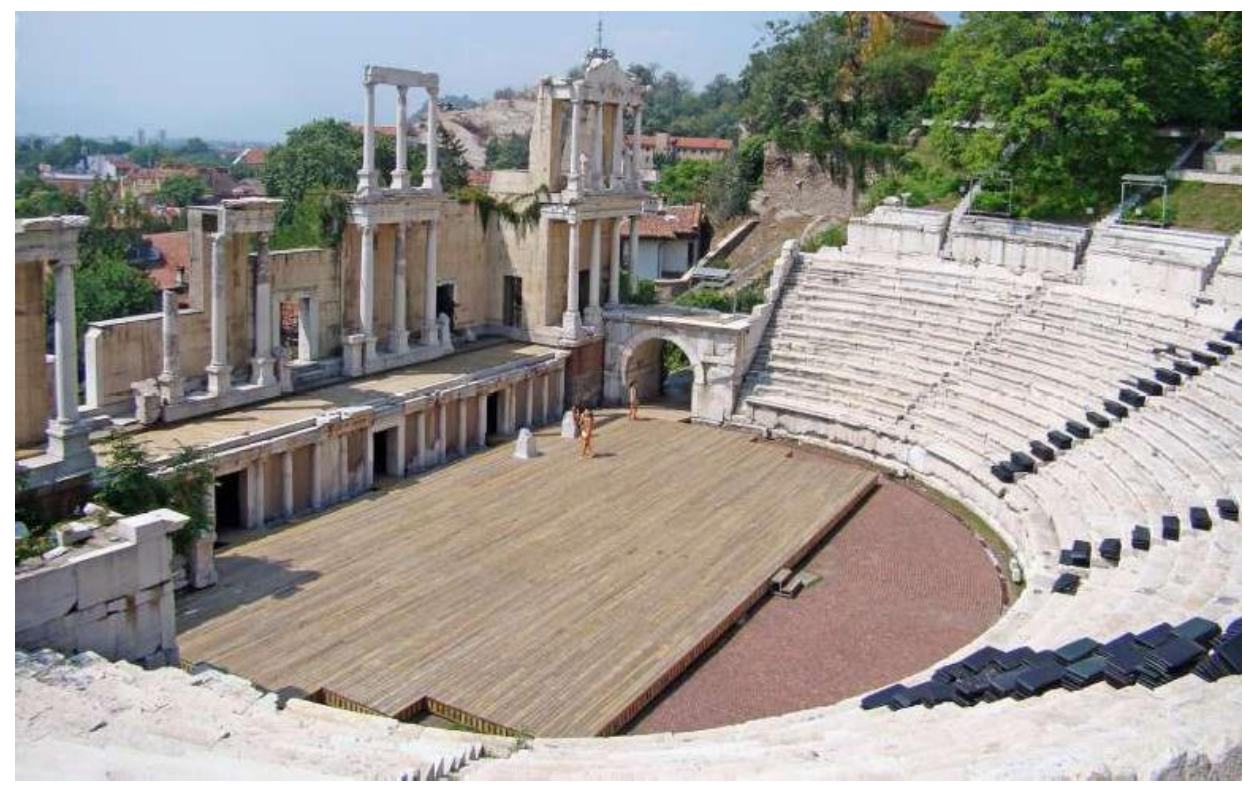

Gambar 3. Forum Yunani (sebagai teater saat tidak di gunakan) Sumber: https://id.pinterest.com/pin/208432288987969136

\section{Food Court}

Menurut manifesto Eataly "Good food brings us all together and helps us find a common point of view" atau "Makanan enak membawa kita Bersama dan membantu kita menyatukan suatu pandangan. James $W$. Rouse mempunyai mimpi menciptakan "community picnic" dalam shopping mall yang di bangun olehnya. Beliau menciptakan The Eaton Center, Toronto, untuk mencoba mengintregasikan dan menyatukan banyak restaurant di satu area pada mall tersebut dan memiliki tempat duduk yang banyak dan bersifat publik. Hasilnya, pengunjung pada The Eaton Center ini meningkat drastis di banding mall lain yang di buka oleh Rouse, dan pengunjung bertahan $20 \%$ lebih lama di mall yang berarti penjualan lebih banyak. Melihat 
kesuksesan Rouse ini, banyak developer lain mengambil idenya dan membuka foodcourt masing masing dimana ada kios kios yang dapat di sewa oleh vendor dan tempat makan tempat yang luas untuk makan bersama-sama.

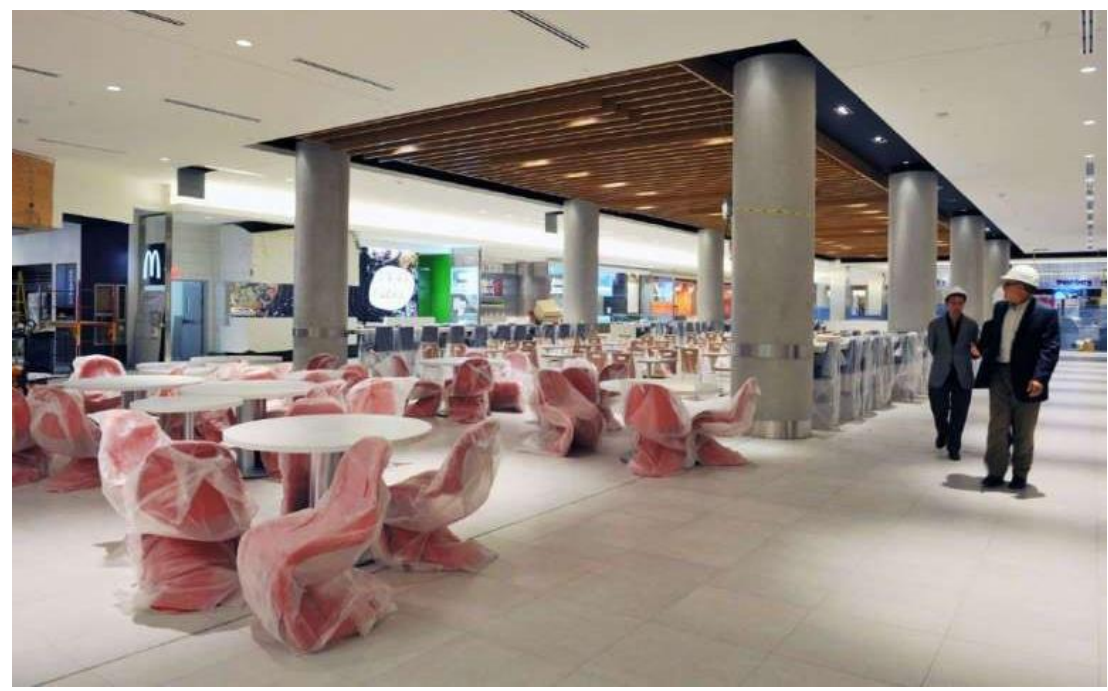

Gambar 4. The Eaton Center Toronto, Food Court (Setelah renovasi)

Sumber:

https://www.thestar.com/life/food_wine/2011/08/24/the_eaton_centres_48million_food_court_makeover.html

Sekarang Food court merupakan sebuah tempat makan yang terdiri dari counter-counter makanan yang menawarkan aneka menu yang bervariasi. Food court aadalah area makan yang terbuka dan bersifat informal dengan tema yang unik dan beragam. Area ini biasanya terdapat di mall-mall atau pusat perbelanjaan, perkantoran modern, universitas, atau sekolah-sekolah yang modern (Olsen, 2003).

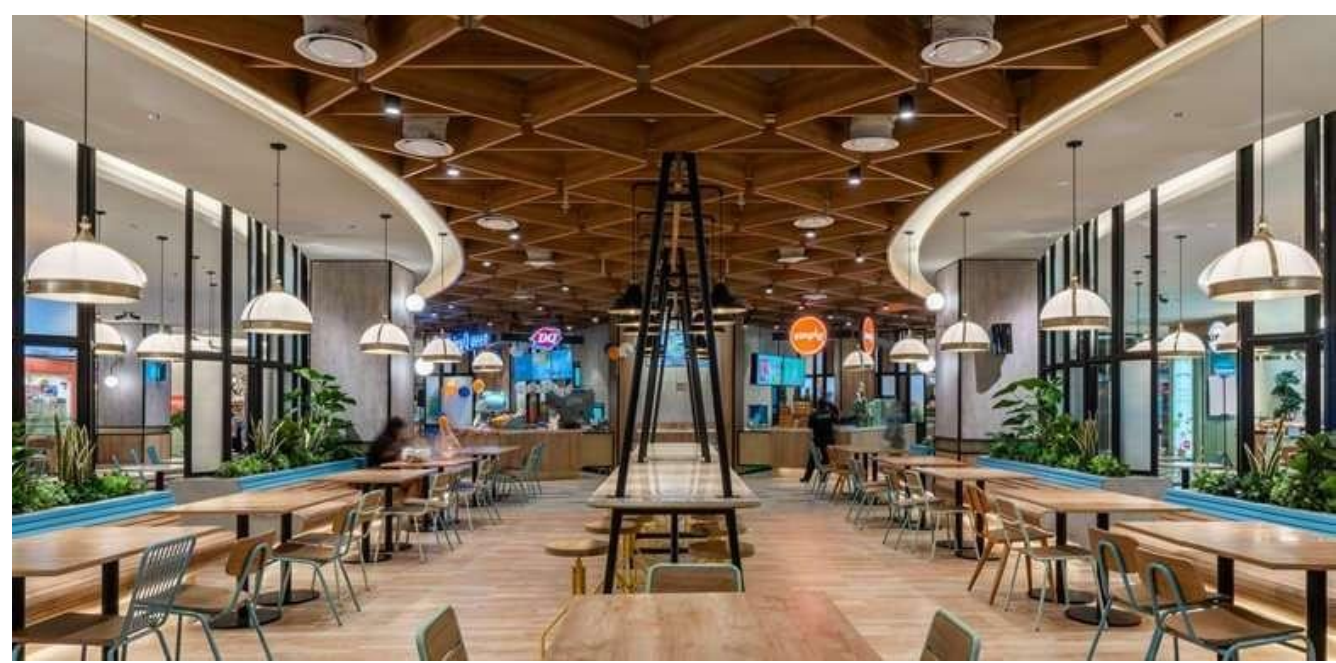

Gambar 5. Food Empire, Emporium Mall Pluit, by Metaphor, Interior Architecture Sumber: https://www.the-metaphor.com/project-detail/67

\section{METODE}

Metode yang di gunakan penulis dimulai dari sebuah kelurahan yang di lihat secara issue/ permasalahan yang terjadi di area tersebut. Lalu pemilihan tapak yang sesuai dan dapat menjadi area yang beneficial dan setara bagi permasalahan. Lalu ada pengumpulan data dan aktifitas tapak, pengelompokan dan pemetaan fungsi, dan trial and error gubahan massa. 


\section{DISKUSI DAN HASIL}

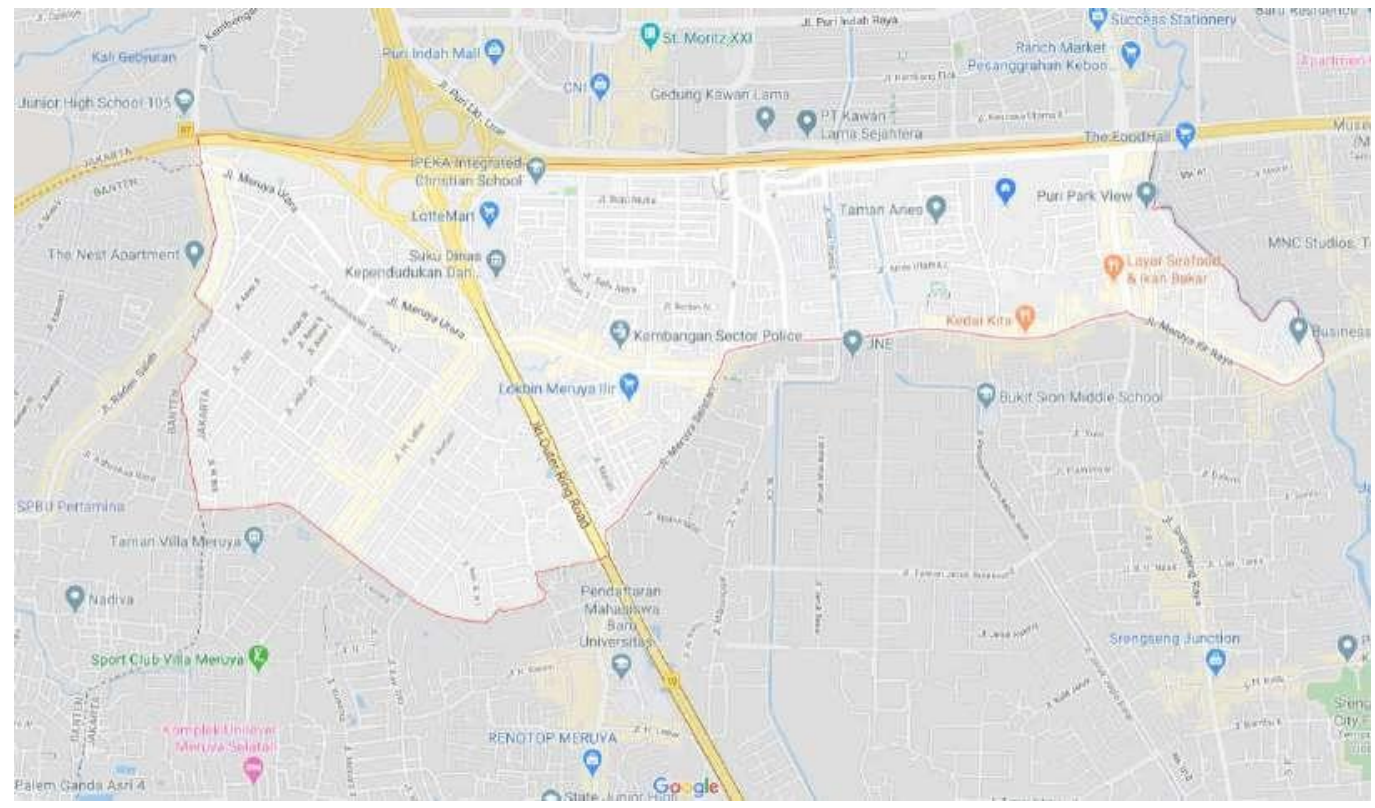

Gambar 6. Kelurahan Meruya Utara, Kecamatan Kembangan, Jakarta Barat Sumber: https://www.google.co.id/maps/place/North+Meruya

\section{Pengumpulan Data Tapak Serta Data Aktifitas}

Yang dapat para warga lakukan bersama, data warga dari mayoritas umur hingga mayoritas etnis. Daerah ini memiliki 52.434 warga, 26.488 warga lelaki dan 25.986 warga perempuan. Dengan tingkat kelahiran 178 jiwa dan tingkat kematian pada 178 pada tahun 2018 sehingga memberi rasio pertumbuhan penduduk terhadap tingkat kematian 4,4:1. Meruya Utara juga memiliki 26 TK, 18 SD, 16 SMP, 10 SMA. Dari angka ini dapat disimpulkan bahwa pertumbuhan angka warga akan terus bertambah setiap tahunnya dan bertumbuh dengan sangat cepat (BPS, 2018).

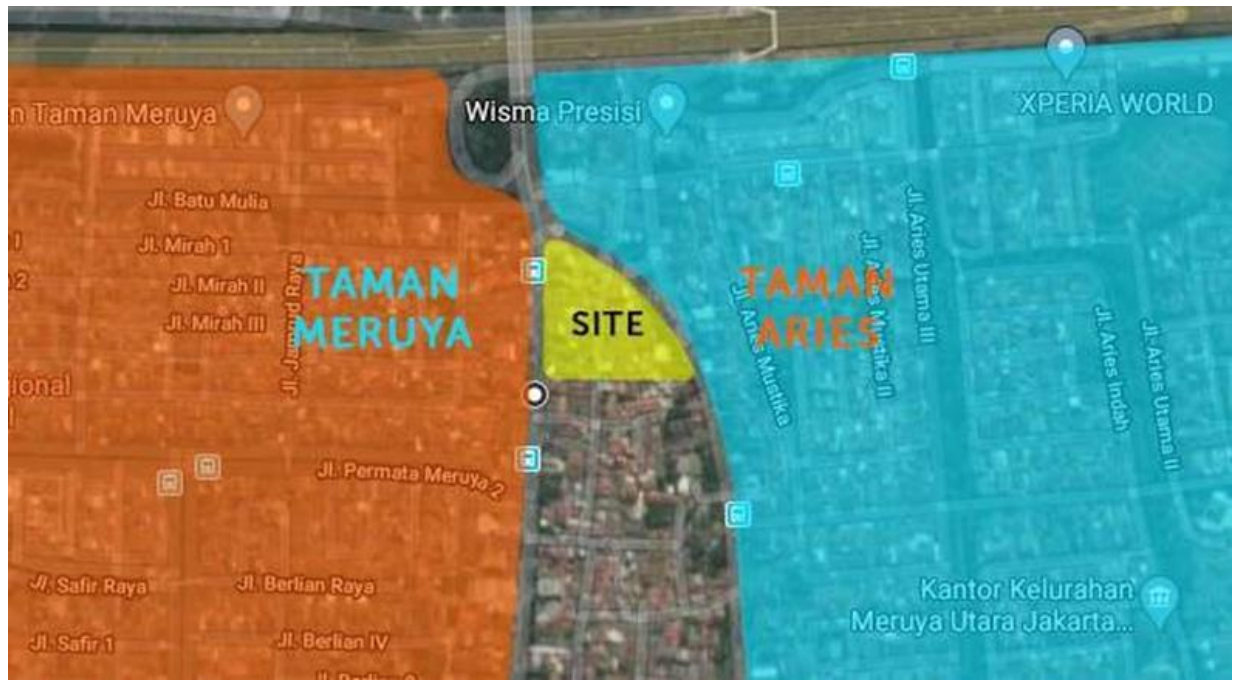

Gambar 7. Lokasi Site

Sumber: Dokumentasi Pribadi, 2020

Tanah ini memiliki peruntukan R5, KDB 65\%, KLB 1.9, KB 3, KTB 0, KDH 15. Dengan luas Site ber ukuran $8.600 \mathrm{~m}^{2}$ ini artinya memiliki KDB $5.250 \mathrm{~m}^{2}$, KLB 10.497,5 $\mathrm{m}^{2}$, ketinggian bangunan 3 lantai dan KDH minimal $1290 \mathrm{~m}^{2}$. Tapak ini di pilih karena berpotensi dapat menjembatani 
antara kedua belah pihak warga serta menjadi tempat yang dapat dengan mudah di akses kedua belah pihak warga dengan adil tanpa ada bermain favorit.

\section{Pemetaan Aktifitas}

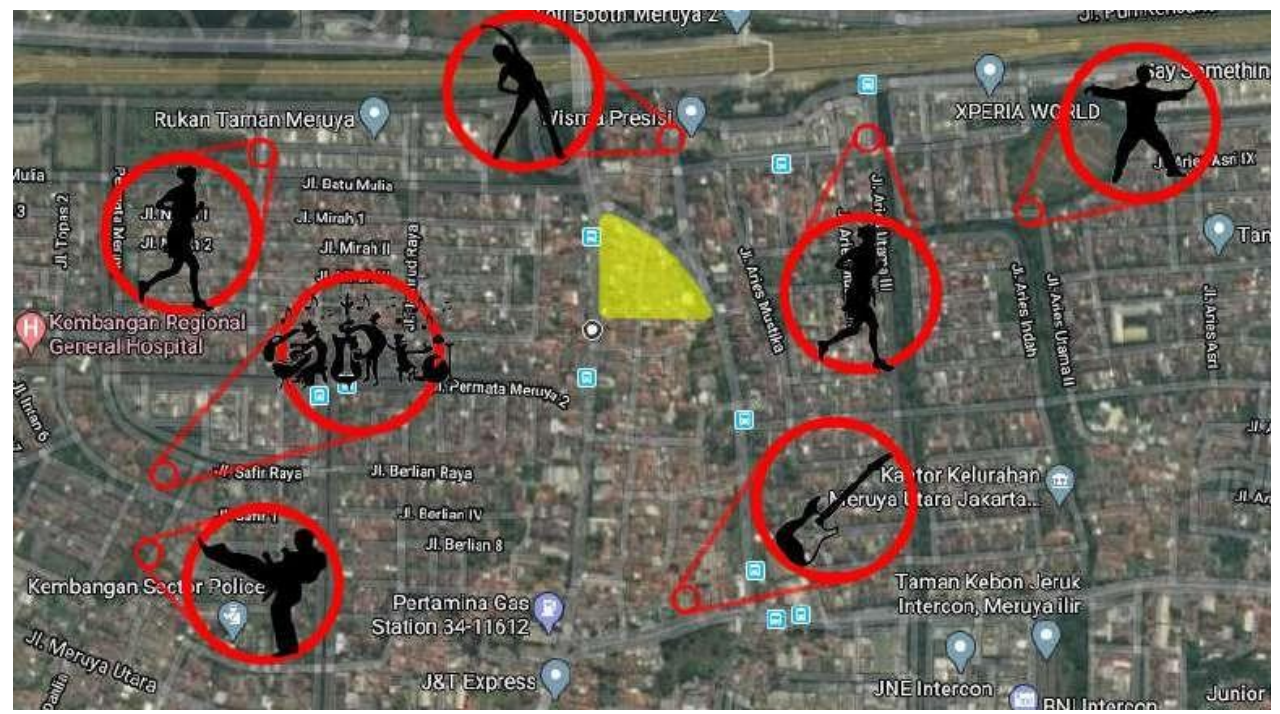

Gambar 8. Pemetaan aktifitas warga Meruya Utara

Sumber: Dokumentasi Pribadi, 2020

Dari pemetaan ini ada beberapa aktifitas yang di lakukan Bersama sama, dan berpotensi untuk menjadi aktifitas interaktif antar kedua pihak warga. Aktifitas tersebut banyak yang di lakukan pada tempat yang tidak pas seperti senam pagi Taichi dengan cara menutup gang pada pagi hari, dan senam poco poco pukul 21.00 di dekat pintu keluar tol meruya alhasil menutup $1 / 4-1 / 2$ jalan keluar tol. Ada pula jogging oleh kedua belah pihak dan di lakukan di pinggir jalan raya tanpa adanya sebuah side walk atau trotoar. Dengan semua data yang dikumpul, dianalisikan sehingga membuat tebel kebutuhan serta jadwal aktifitas.

Tabel 1. Aktifitas dan jadwalnya

\begin{tabular}{c|c|c}
\hline Aktifitas & Area & Jadwal \\
\hline $\begin{array}{c}\text { Komersil } \\
\text { Makanan/Minuman }\end{array}$ & Foodcourt & Harian \\
\hline Makan / minum & Area Makan - lapangan terbuka & Harian \\
\hline Membaca Buku & Area Membaca - lapangan terbuka & Harian \\
\hline Mengerjakan Tugas & Area Membaca & Harian \\
\hline Nongkrong / & Lapangan terbuka & Harian \\
\hline Bermusyawarah & Forum (Panggung) & Bulanan \\
\hline Kontas Drama & Forum (Panggung) & Tahunan \\
\hline Forum Aspirasi Warga & Forum (Panggung) & Bulanan \\
\hline Pencak silat & Komersil Makanan/Minuman & Harian \\
\hline Senam poco-poco & Makan / minum & Harian \\
\hline Taichi & Membaca Buku & Harian \\
\hline Jogging & Mengerjakan Tugas & Harian \\
\hline Pentas Musik Harian & Nongkrong / Bermusyawarah & Harian \\
\hline Pentas Musik Mingguan & Pentas Drama & Mingguan \\
\hline Pentas Musik Bulanan & Konser Tahunan & bulanan \\
\hline Pelatihan Memasak & Forum Aspirasi Warga (Bulanan) & Mingguan \\
\hline
\end{tabular}

Sumber: Dokumentasi Pribadi, 2020 


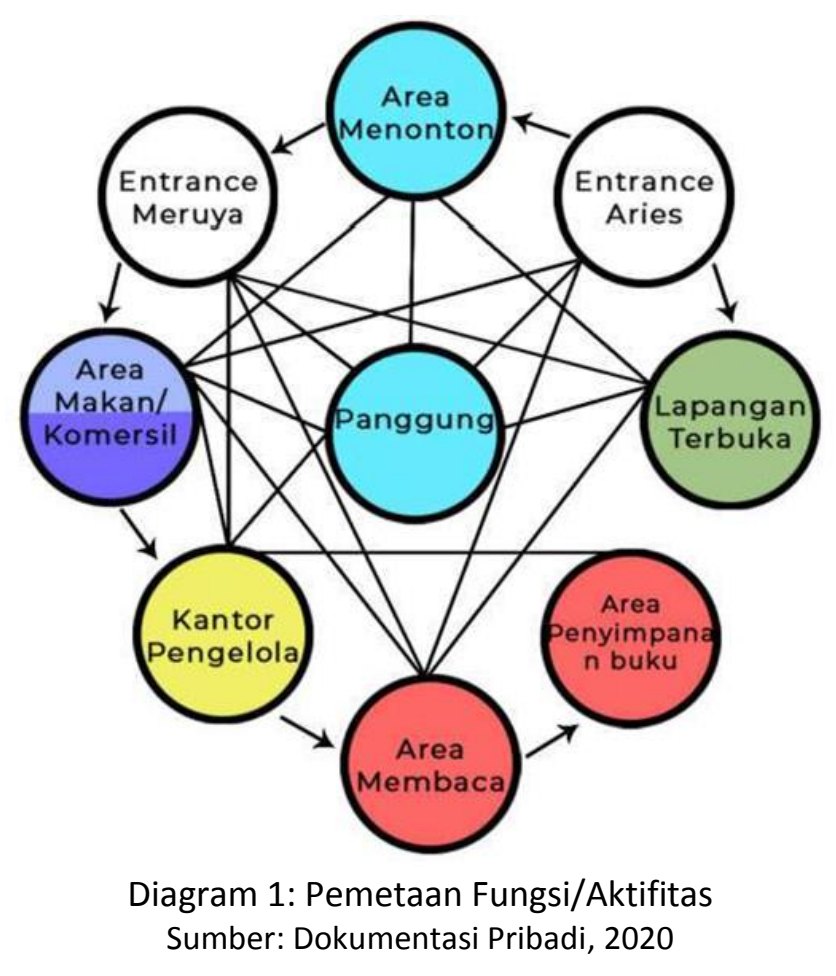

Lalu mulai pemilihan cara masuk warga dari kedua pihak warga dan memetakan kebutuhan kebutuhan warga dengan diagram lalu menerjemahkanya ke dalam bentukan denah dan gubahan massa. Setelah trial dan error gubahan, adanya gubahan baru di integrasikan dengan hal-hal lokal dan memiliki arti bagi warga sekitar dan melakukan trial and error sekali lagi.

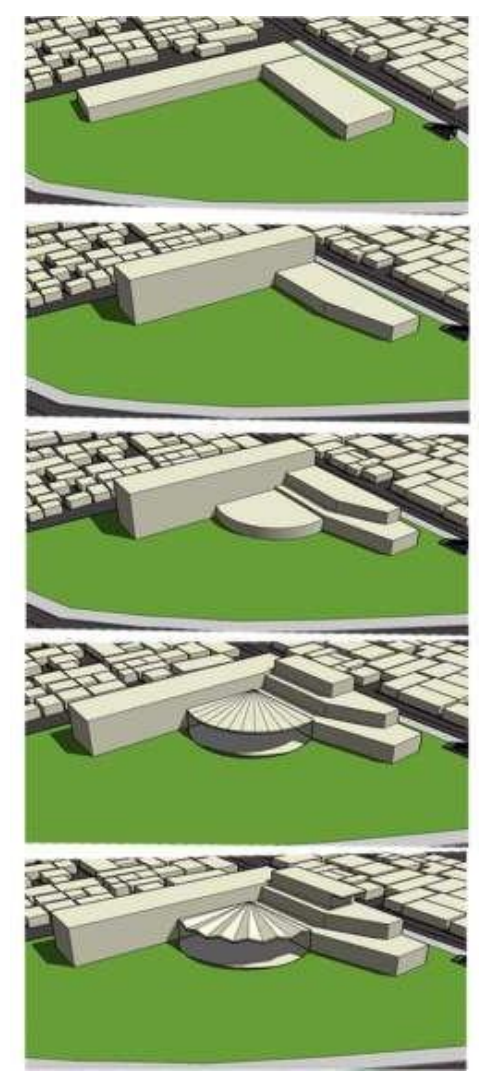

Gambar 9. Perkembangan Gubahan Massa

Sumber: Dokumentasi Pribadi, 2020 
Bedasarkan analisa yang didapatkan dan dipelajari dari lingkungan sekitar, menghasilkan faktor- faktor yang membantu dalam pembentukan massa yaitu;

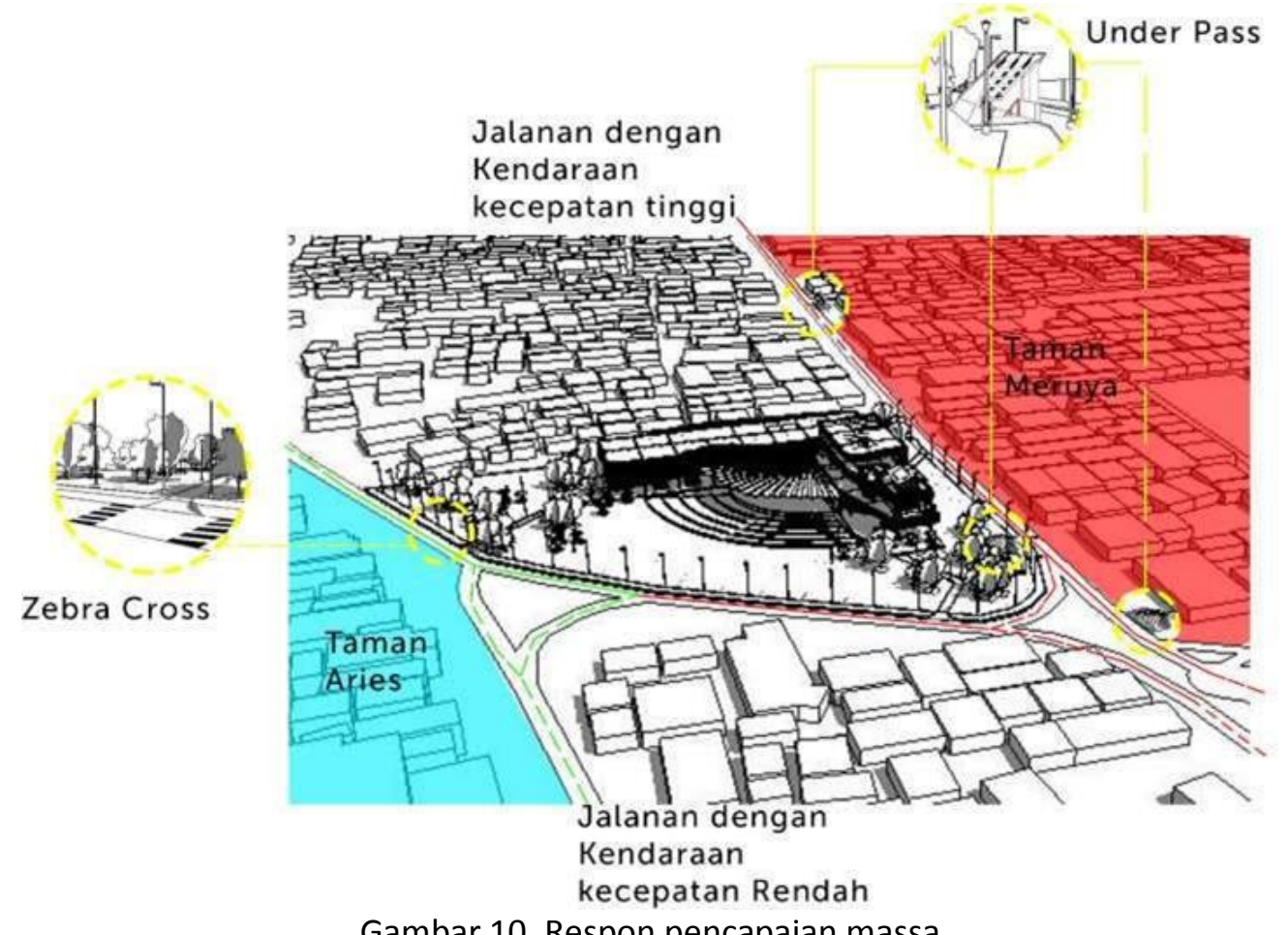

Gambar 10. Respon pencapaian massa

Sumber: Data Pribadi, 2020

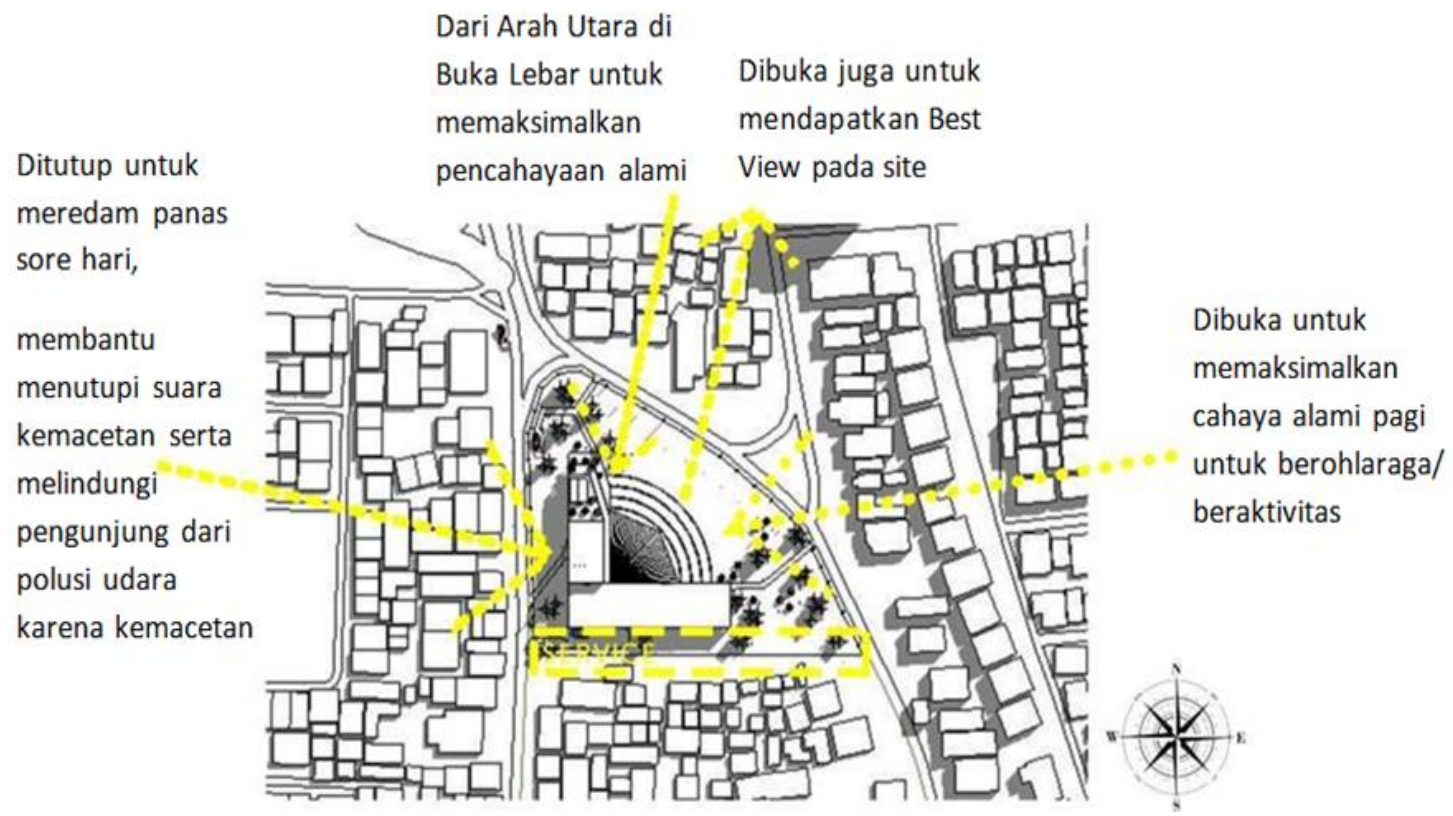

Gambar 11. Respon terhadap matahari dan polusi Sumber: Dokumentasi Pribadi, 2020 


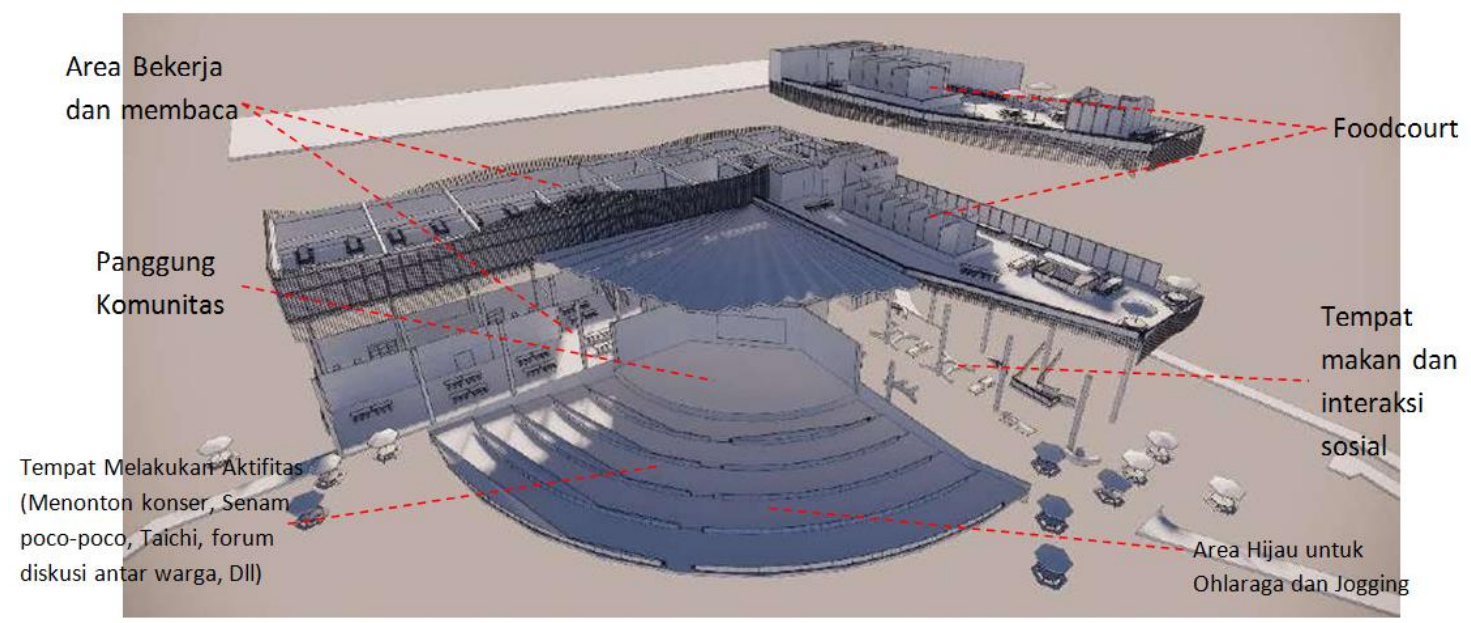

Gambar 12. Aksonometri Bangunan, Penjelasan konsep

Sumber: Dokumentasi Pribadi, 2020

Dengan dua kubu warga yang berbeda, pertama-tama warga akan di perkenalkan dulu dengan program yang terlebih dahulu lebih gampang di terima jika di lakukan bersama, seperti program food court dan co-working space. Pada program itu warga yang berdatangan dan menikmati programnya akan mulai terbiasa bergabung satu sama lain karena makan merupakan kebutuhan pokok. Dengan demikian akan mulai ada rasa 'level' sesuai dengan buku Oldenberg, rasa kesetaraan ini akan membuat warga lebih nyaman untuk melakukan hal keduaa yaitu untuk tetap berada di tempat tersebut dan duduk bersantai, dengan demikian warga akan melakukan observasi bangunan dan melihat aktifitas apa saja yang di tawarkan.

Introduksi terhadap beberapa program yang biasa di lakukan para warga di daerah masing masing pada bangunan ini akan menarik perhatian para warga dari dua kubu untuk datang dan melakukan aktifitasnya bersama. Terutama pada aktifitas yang biasanya di lakukan pada tempat yang tidak sesuai, hal ini dapat menarik para warga dari masing masing area untuk datang melakukan aktifitas tersebut di tempat yang lebih layah dan sudah di sediakan proyek ini. Serta dapat menarik perhatian warga yang belum pernah mengetahui aktfitas tersebut dan mendorong mereka untuk ikut dan melakukanya bersama. Itulah strategi yang akan di gunakan untuk mencoba mempersatukan para warga dari kedua kubu ini.

\section{KESIMPULAN DAN SARAN}

\section{Kesimpulan}

Pada proses perancangan ini, penulis berusaha untuk menerapkan fungsi sebuah third place yang tepat dalam memenuhi atau melengkapi kebutuhan, serta mencoba menyatukan Kembali hubungan antara masyarakat di Meruya Utara. Banyak kegiatan yang di lakukan warga Meruya Utara ini tidak memiliki tempat yang layak, dari aktifitas yang di lakukan di pinggir jalan raya hingga aktifitas yang dilakukan dengan penutupan jalanan. Banyak warga yang jika sudah pulang tidak ada keinginan untuk keluar dan bersosialisasi degan warga lain menghasilkan rasa yang tidak familiar, serta membuat warga enggan berbicara, sehingga jika timnulnya masalah, langsung terjadi kebencian. Banyak siswa dan mahasiswa yang kekurangan tempat kerja juga sehingga banyak yang melakukanya di food court dan tempat lain yang kurang layak untuk bekerja. Dengan 'Gelanggang Dia.Lo.Gue' di harapkan aktifitas pada daerah meruya utara di alokasikan ke dalam Gelanggang Dia.Lo.Gue dan tercipta lingkungan yang lebih layak sehingga warga dapat dengan aman dan nyaman melakukan aktifitas tersebut. Dengan ramainya aktifitas pada Gelanggang Dia.Lo.Gue di harapkan juga timbul interaksi sosial, gelanggang ini di lengkapi dengan tempat duduk dan taman hijau yang luas untuk piknik sehingga mendorong para warga untuk berinteraksi sosial. 


\section{Saran}

Saran penulis adalah buatlah third place yang menyenangkan di antara ruang pertama dan kedua, karena ruang ini selain di pergunakan untuk interaksi sosial, sangat dibutuhkan di seluruh kehidupan manusia untuk mendukung jatidiri dan memotivasi agar tetap menjalankan aktivitasnya dengan maksimal.

\section{REFERENSI}

BPS. (2018). Kembangan Dalam Angka. Jakarta: Badan Pusat Statistik Kota Administrasi Jakarta Barat

History.com. (2018, Agustus 21). Retrieved from www.history.com/topics/ancient- rome: https://www.history.com/topics/ancient-rome/roman-forum Juhri, H. (2020, 02 03). Petinggi Warga Betawi. (K. Hartanto, Interview)

King, I. T. (2008). The Political Theory of Darwinism: Zoon Politikon and the Evolutionary Case for Social Democracy. In I. T. King, The Political Theory of Darwinism: Zoon Politikon and the Evolutionary Case for Social Democracy. USA: Edwin Mellen Pr.

Stern, T. (2017). The Philosophy of Theatre, Drama and Acting. USA: Rowman \& Littlefield International.

Oldenberg, R. (2002). Celebrating the Third Place: Inspiring Stories About the "Great Good Places" at the Heart of Our Communities. Florida: Da Capo Press.

Olsen, J. (2003). Better Places, Better Lives: A Biography of James Rouse. Washington DC: ULIthe Urban Land Institute. 